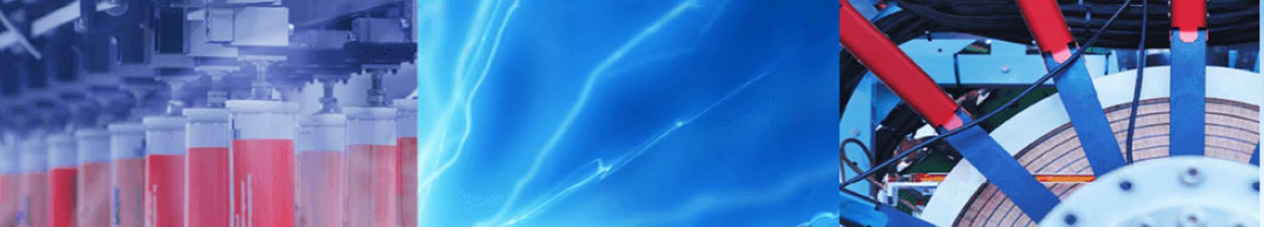

Research Article

\title{
Effect of cyclic heating on some engineering characteristics of some soils from Ilorin, Nigeria
}

\author{
Olubunmi Oluwadare Owoyemi ${ }^{1}$ [D $\cdot$ Lekan Olatayo Afolagboye ${ }^{2}$
}

Received: 15 May 2020 / Accepted: 27 October 2020 / Published online: 11 November 2020

(c) Springer Nature Switzerland AG 2020

\begin{abstract}
This work investigates probable changes during repeated heating and cooling cycles on some index and engineering properties of some lateritic soils. Bulk soil samples were taken within llorin metropolis. These samples were oven dried for $24 \mathrm{~h}$ at $110^{\circ} \mathrm{C}$ and cooled naturally to room temperature. This procedure was repeated four times. The effect of cyclic heating and cooling on various soil properties including Atterberg limits, particle size distribution, moisturedensity relationship and California bearing ratio (CBR) were investigated. The results show that maximum dry density (MDD) reduced consistently with repeated heating and cooling while optimum moisture content (OMC) increased. CBR increased with repeated heating and cooling up to $23.5 \%$. A percentage decrease in liquid limit up to $25 \%$ was recorded while plastic limit and plasticity index reduced in all samples. Increase in CBR is an indication of increase in strength with repeated heating while the decrease in MDD is an indication of reduced density on account of increase in OMC of the soil samples with repeated heating.
\end{abstract}

Keywords Lateritic soil · Heating · Cooling · Compaction · Consistency limits · California bearing ratio

\section{Introduction}

In tropical and subtropical parts of the world (e.g. Nigeria, China, and Brazil), residual lateritic soils are common and widely distributed soil [1,2]. They are common geomaterials used in various engineering structures such as pavements, compacted clay liners, earth dams, etc. [1-3]. The engineering properties of the soils are influenced by the several complex interactions between the compositional and environmental factors [4]. Among the environmental factors, temperature is an important property that can affect the properties of soils and hence the effects of temperature on engineering performance of soils is increasingly receiving attention in geotechnical engineering [4-6]. This is because soils may experience induced temperature changes from engineering structures such as groundwater heat pump [7], hot buried or oil and gas pipelines, buried electricity or high-voltage cables [8], and radioactive waste depositories [9]. In addition, the induced temperature change may also be as a result of daily and seasonal thermal cycles as observed in clay liner and embankments made of lateritic soils [10] or through natural wild forest fires and thermal remediation processes $[11,12]$.

Previous works have shown that variations in the induced temperature in soils (either through natural means or engineering structures) can affect the index, hydraulic, compaction, consolidation, and strength properties of soils $[6,13,14]$. Abu-Zreig et al. [15] investigated the effect of increasing temperature on the properties of clayey soils and reported that as the temperature increases (beyond $100^{\circ} \mathrm{C}$ ), the Atterberg limits, swelling pressure,

Olubunmi Oluwadare Owoyemi, lade.owoyemi@gmail.com; Lekan Olatayo Afolagboye, afotayour@hotmail.co.uk|'Department of Geology, College of Pure and Applied Science, Kwara State University, Malete, PMB, Ilorin 1530, Nigeria. ${ }^{2}$ Department of Geology, Faculty of Science, Ekiti State University, Ado-Ekiti, Nigeria. 
optimum moisture content and unconfined compressive strength of the soil decrease. The effect of increasing temperature on tropical black cotton soils was studied by Gadzama et al. [14] and they reported that properties such liquid limit, plastic limit, and California Bearing Ratio (CBR) decreased while the maximum dry density increased as the temperature increases. No general trend was established between the optimum moisture content, plasticity index and temperature by the authors.

Different papers have also been published to evaluate the influence of elevated temperature on the swelling and consolidation behaviour of different soils [13, 16-18]. According to Romero et al. [19], the volume of normally and highly overconsolidated clays contracts and expands, respectively, when subjected to elevated temperature. Abuel-Naga et al. [20] and Sultan et al. [17] stated that preconsolidation pressure increased as the temperature increases while Moh et al. [21] reported a decrease in preconsolidation pressure as the temperature increases. Similarly, Abuel-Naga et al. [20] reported that compression and swelling coefficients are influenced by increase in temperature. Previous works on the effect of temperature on the permeability of soils showed that increase in temperature also lead to increase in permeability of soil obtained either through direct or in direct methods $[13,16,20]$.

Review of the past works have shown that although there are numerous studies on the effect of elevated temperature on the behaviour of soil but the effect of subjecting a soil to repeated or cyclic elevated temperature has not been studied. Indeed, most of the previous studies have studied the influence of different temperature level on the engineering properties of soils that are mostly nontropical or residual soils. This work therefore investigates the influence of repeated heat treatment at $110{ }^{\circ} \mathrm{C}$ and cooling on the physical properties of some lateritic soils. We selected this temperature $\left(110^{\circ} \mathrm{C}\right)$ as it similar to or slightly higher than the prevailing temperature conditions observed around some engineering structures. For instance, soil may be exposed to an elevated temperature of more than $120^{\circ} \mathrm{C}$ during tunnel fires [22]. In addition, the design temperature for buffers in high level waste disposal sites must be around $90^{\circ} \mathrm{C}$ [23]. For buried power cables, $80^{\circ} \mathrm{C}$ has been reported as the highest temperature around the cable and $60{ }^{\circ} \mathrm{C}$ when the distance is about $0.25 \mathrm{~m}$ from the cables [24].

\section{Location of study area}

The study area, llorin, is located in the humid tropical part of Nigeria. The city serves as administrative center of Kwara State and it is rapidly developing and expanding with the construction of new engineering structures such as highways, bridges, and buildings daily. The distinct raining and dry seasons and suitable thick vegetation enhance the formation of laterite/lateritic soils in the study area. llorin is among the areas underlain by the rocks of the Precambrian basement complex rocks of Southwestern Nigerian [25]. Figure 1 shows the geological map of the study area with the sampling locations. The studied lateritic soils developed over granite gneiss and migmatite gneiss, which happens to be most extensive rock unit of the Precambrian basement complex rocks of Southwestern Nigerian. Geological field mapping revealed that the rocks mixture of felsic and mafic minerals. The major minerals in the rocks include quartz, feldspar, biotite, and hornblende. The two parent rocks are foliated with pegmatite and quartz veins intrusions.

\section{Methodology}

The lateritic soil samples used in this study were obtained from four different parts of Ilorin where road construction have just exposed fresh lateritic soil profile. Four bulk residual lateritic soils samples were obtained from test pit at depth of $0.75 \mathrm{~m}$ at the different locations. Samples taken at this depth are not exposed directly to sunlight and are expected to have their natural moisture and sensitivity preserved. The collected samples were air-dried before testing in the laboratory for three weeks and drying stopped when the weight of the samples became constant. Index and engineering tests including consistency limits, grain size analysis, California bearing ratio (CBR), and compaction test were determined. To determine the effect of repeated heating and cooling on the air-dried soils, the properties of the air-dried samples, which were not exposed to repeated heating and cooling, were compared to the properties of the soil samples subjected to repeated heating and cooling.

The repeated heating and cooling of the lateritic soils were carried out using the following procedure. The airdried soil samples were oven dried at $110^{\circ} \mathrm{C}$ for $24 \mathrm{~h}$ and allowed to cool at room conditions for about $12 \mathrm{~h}$. This process of heating and cooling was repeated four times (Four cycles). After the completion of the 4th cycle, grain size distribution and Atterberg limits tests were carried out. However, OMC, MDD and CBR were carried out after each cycle in order to investigate the changes in these properties in between each heat treatment cycle. The CBR was determined after the samples were compacted using the standard Proctor energy at optimum moisture content (OMC). Grain size distribution and Atterberg limits were not determined at each cycle to minimize soil wastages and avoid extra reheating of the soil during determination of moisture contents associated with determination 


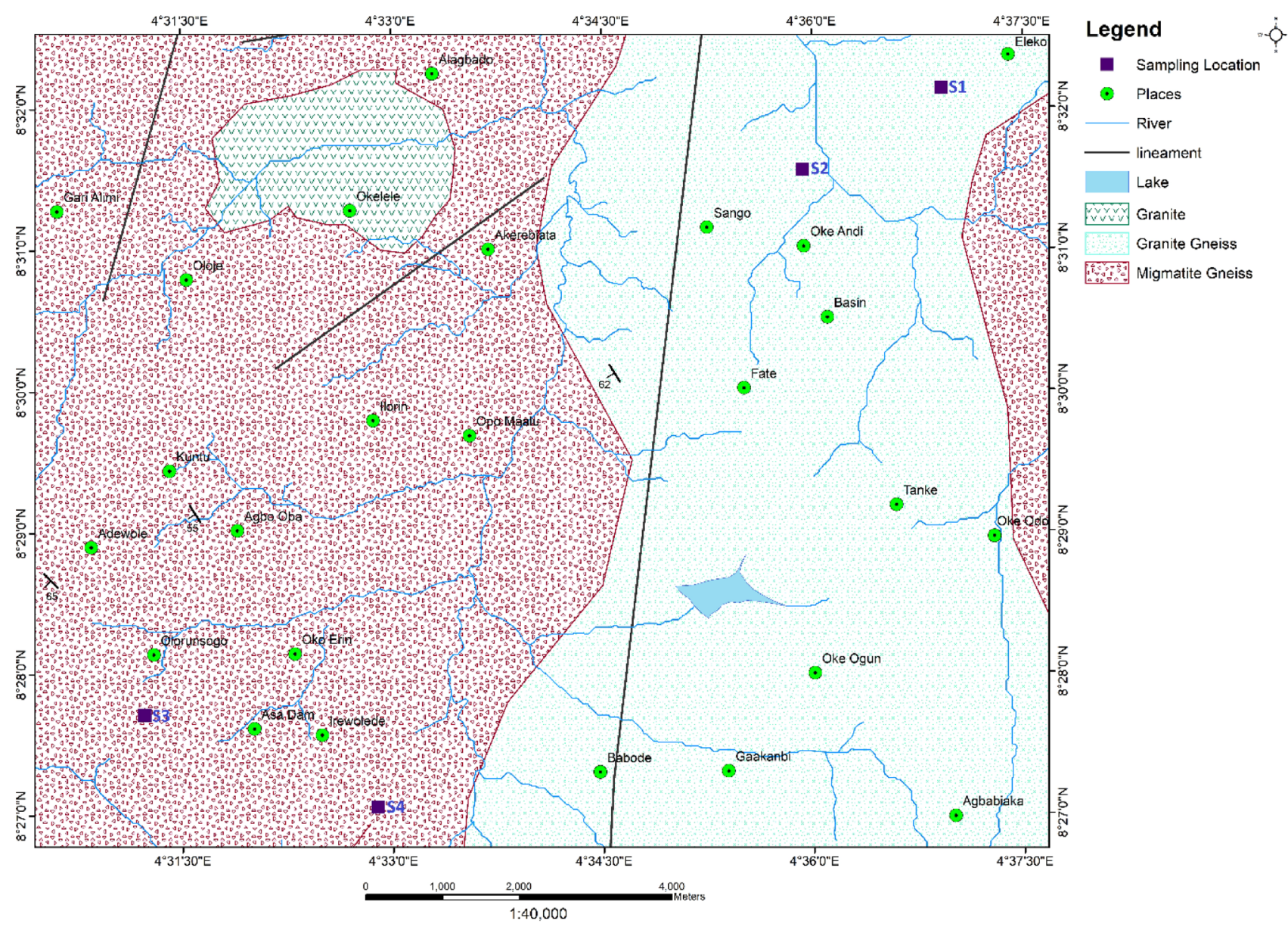

Fig. 1 Geology map of the study area showing location of the sampling area

of liquid and plastic limits. All the soil properties investigated were determined in accordance with procedure of BS 1337 [26]. Thin sections of the rock samples from which the lateritic soils were derived were prepared. Petrographic study was carried out in accordance with the standard procedures for petrographic examination of rocks given by the International Society for Rock Mechanics [27]. Mineralogical and textural properties were investigated by using a polarising microscope and analysing the images. The modal composition was obtained using the point counting method.

\section{Results and discussion}

\subsection{Physical properties of the studied soils before heat treatment}

Four bulk lateritic soil samples were taken at different locations shown in Fig. 1. Two of the soil samples are coarse grained while two classify as fine-grained soils

Table 1 Physical properties of the studied soils before heat treatment

\begin{tabular}{lllll}
\hline Properties & $\mathrm{S} 1$ & $\mathrm{~S} 2$ & $\mathrm{~S} 3$ & $\mathrm{~S} 4$ \\
\hline Liquid limit (\%) & 30 & 42.5 & 38.7 & 44 \\
Plastic limit (\%) & 12 & 22.5 & 19.4 & 21.4 \\
Plasticity index (\%) & 18 & 20 & 19.3 & 22.6 \\
Maximum Dry Density $\left(\mathrm{kN} / \mathrm{m}^{3}\right)$ & 1750 & 1800 & 1900 & 1700 \\
Optimum moisture content (\%) & 13 & 11 & 10 & 16 \\
California Bearing Ratio (\%) & 53 & 91 & 27 & 11 \\
Particle size distribution & & & & \\
Gravel (\%) & 8 & 14 & 2 & 0 \\
Sand (2 mm-75 mm) (\%) & 62 & 50 & 26 & 35 \\
Silt (75 mm-2 $\mu \mathrm{m})(\%)$ & 6 & 10 & 41 & 18 \\
Clay size fraction (<2 $\mu \mathrm{mm})(\%)$ & 24 & 26 & 31 & 47 \\
Activity & 0.75 & 0.77 & 0.61 & 0.49 \\
Casagrande Plasticity Classification & $\mathrm{CL}$ & $\mathrm{CL}$ & $\mathrm{CL}$ & $\mathrm{CL}$ \\
\hline
\end{tabular}


under the Unified soil classification system. Table 1 presents the index and engineering properties of the studied soils before being subjected to repeated cycles of heating and cooling. The particle size analysis showed that the lateritic soils were well graded and contained variable amount of fines $(<0.075 \mathrm{~mm})$. For instance, samples S1 and S2 have low amount of fines (30-36\%) while S3 and S4 have high amount of fines (65-72\%). In addition, the coarse portion (gravel + sand contents) of S1 and S2 were generally high compared to S3 and S4. This reflects the influence of the parent rock factor on the grain size distribution of the soils. Figure 2 shows the grain size distribution curves of the studied soils before drying-cooling cycles. The liquid limit values varied between $30 \%$ and $44 \%$ while plasticity index ranged from $18 \%$ to $22.6 \%$. The plot of plasticity indices against liquid limits (Fig. 3), according to Casagrande, classified the soils as inorganic clay of medium plasticity (CL soil). Activity of the clay size fractions of all soil samples indicates that they contain low activity or inactive clay [28] cited in [29]. Owoyemi and Adeyemi [30] also confirmed soils from the region consist mainly of kaolinite as the main clay mineral. The MDD of the soils varied from 1700 to $1900 \mathrm{KN} / \mathrm{m}^{3}$ while the OMC ranged from $11 \%$ to $16 \%$. The CBR of the ranged from $11 \%$ to $91 \%$. The lateritic soil samples with the highest amount of coarse grain size have the highest CBR and lowest OMC values.
Fig. 2 Grainsize distribution curves of the studied soils before heat treatment
Fig. 3 Casagrande Chart comparing the plasticity of the studied soils (Based on Cassagrande [31])
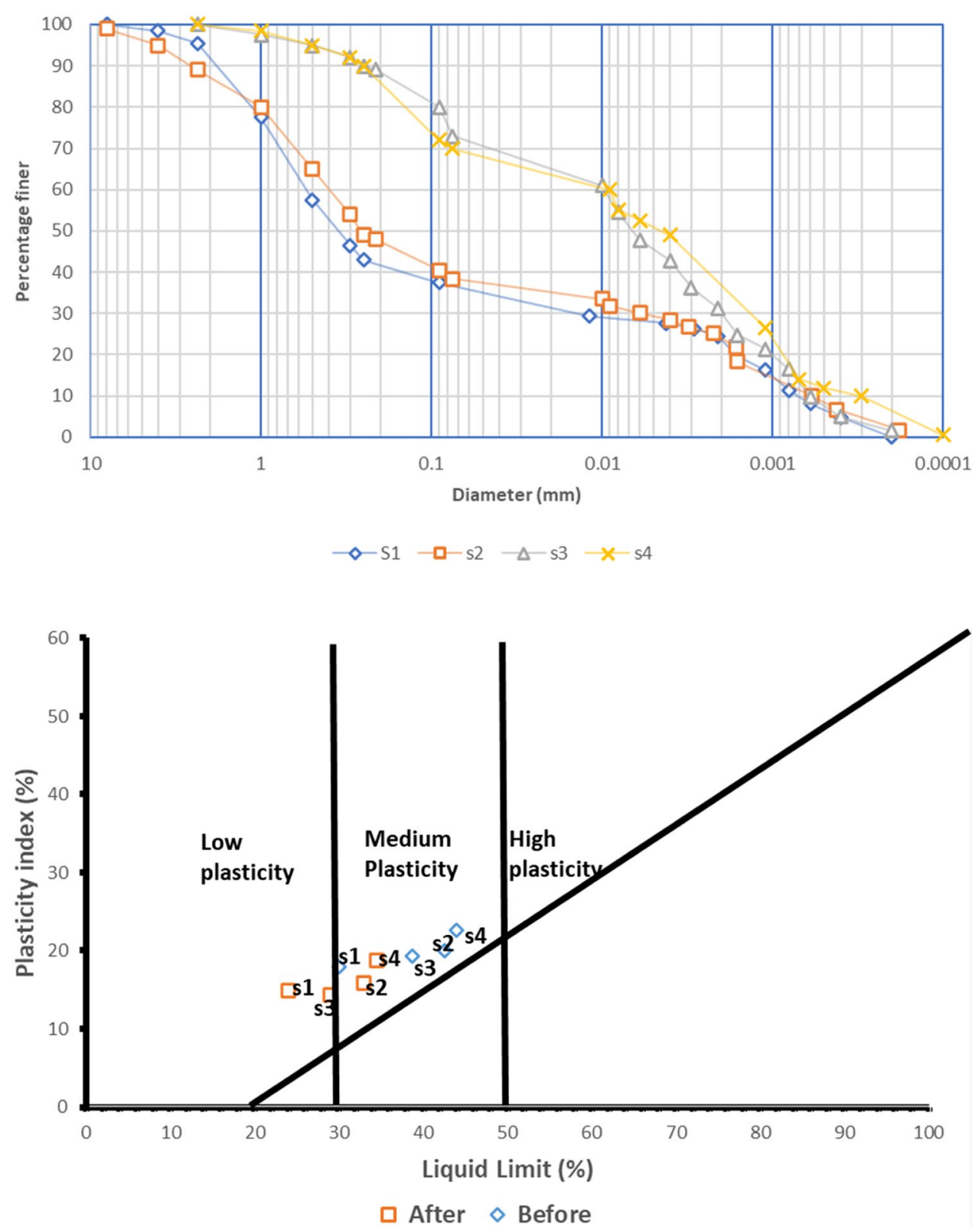


\subsection{Effect of heat treatment on the consistency limits and grain size distribution of the studied soils}

The consistency limits and grain size distribution of the studied soils were tested after the four heating - cooling cycles. This was to check if there are noticeable changes in plasticity, possible aggregation, disaggregation, and mechanical breakdown of the soils particles after going through repeated heating and cooling. Table 2 presents the fractional percentages of the soils according to the grain size curves of the soil samples before and after heating. Minor changes were detected in the grain size distribution characteristic of the studied soils after the four cycles of heating - cooling. For instance, proportion of sand in sample $\mathrm{S} 1$ only increased by $4 \%$ after heating while it remained unchanged in sample 52 . This implies that there is no glaring breakdown of the soil particles or clay particles aggregation due to the four heating and cooling cycles.

Table 3 presents the changes in the liquid and plastic limits of the soil samples after four heating - cooling cycles. Percentage decrease in liquid limit ranged between $19 \%$ and $25 \%$, for plastic limit it ranges between $24 \%$ and $59 \%$ while that of plasticity index is between $7 \%$ and $30 \%$. The reduction in consistency limits with repeated heating could be due to changes in clay size fraction, specific surface area of the soil particles; dehydration and decomposition of soil particles, changes in mineralogy and alteration of microstructure of the soils. Free water, an essential part of the soil, attached to clay particles is normally removed from soil during oven drying and its loss normally destroys the structure of a soil. This eventually affect the index properties of the soil. There is a reduction in plasticity and improvement of the soil with repeated heating. Sample S4 exhibits the highest reduction in liquid limit and plastic limit. This might be attributable to its higher clay content.

Figure 3 shows that all the soils samples classified as medium plasticity soils before repeated heating, but sample S1 and S3 classified as low plasticity soils after cycles of repeated heating. On the other hand, in samples S2 and S4 (Fig. 3) the plasticity level did not change but there is shift in their relative positions on the Casagrande plasticity chart.

\subsection{Effect of repeated heat treatment on moisture dry density relationship}

The MDD and OMC decreases and increases, respectively, with heating - cooling cycles. Table 4 presents the moisture dry density relationships of the soils before and after each heating and cooling cycle. Up to $96 \%$ increase in OMC was recorded at the fourth heating cycle while percentage decrease in MDD after the heating cycles is not more than $12 \%$. Figures $4,5,6$, and 7 shows the variation the moisture dry density relationships of each soil sample with heat treatment. For all the heated samples, the relationship between OMC and MDD remains negative (Fig. 8). This means that MDD decreased as OMC increase. The decrease in the MDD of the soils could be due to the generation or presence of micro-cracks within the soil fabric which could produce voids and fissures during compaction and finally reduced the MDD of the tested soils [14]. Similar behaviour was also obtained by Aldaeef [10] while working on hydraulic performance of compacted clay liners under the influence of both temperature and leachate exposures. The increase in OMC may also be linked to the production of microcracks.
Table 2 Grainsize distribution of soil samples before and after heat treatment

Table 3 Consistency limits of the soils before and after drying cycles

\begin{tabular}{|c|c|c|c|c|c|c|c|c|}
\hline \multicolumn{5}{|c|}{ Before heat treatment } & \multicolumn{4}{|c|}{ After heat treatment } \\
\hline Sample & \%gravel & \%sand & \%silt & \%clay & \%gravel & \%sand & \%silt & \%clay \\
\hline S1 & 8 & 62 & 6 & 24 & 8 & 66 & 4 & 22 \\
\hline S2 & 14 & 50 & 10 & 26 & 14 & 50 & 12 & 24 \\
\hline S3 & 2 & 26 & 41 & 31 & 2 & 26 & 42 & 30 \\
\hline S4 & 0 & 35 & 18 & 47 & 0 & 35 & 19 & 48 \\
\hline
\end{tabular}

\begin{tabular}{|c|c|c|c|c|c|c|}
\hline \multirow[t]{2}{*}{ Sample } & \multicolumn{2}{|c|}{ Liquid limit (\%) } & \multicolumn{2}{|c|}{ Plastic limit (\%) } & \multicolumn{2}{|c|}{ Plasticity index (\%) } \\
\hline & Before & After & Before & After & Before & After \\
\hline S1 & 30 & 24 & 12 & 9.1 & 18 & 14.9 \\
\hline S2 & 42.5 & 35 & 22.5 & 15.8 & 20 & 18.7 \\
\hline S3 & 38.7 & 29 & 19.4 & 14.6 & 19.3 & 14.4 \\
\hline S4 & 44 & 33 & 21.4 & 8.8 & 22.6 & 15.9 \\
\hline
\end{tabular}


Table 4 OMC and MDD values attributable to each wetting cycle

\begin{tabular}{|c|c|c|c|c|c|c|}
\hline \multirow[t]{2}{*}{ Sample } & \multirow[t]{2}{*}{ MDD/OMC } & \multirow[t]{2}{*}{ Before heating } & \multicolumn{4}{|c|}{ Heating cycle } \\
\hline & & & 1 & 2 & 3 & 4 \\
\hline \multirow[t]{2}{*}{ S1 } & OMC (\%) & 13 & 15 & 16 & 19.5 & 21 \\
\hline & $\operatorname{MDD}\left(\mathrm{kg} / \mathrm{m}^{3}\right)$ & 1750 & 1710 & 1680 & 1620 & 1550 \\
\hline \multirow[t]{2}{*}{ S2 } & OMC (\%) & 11 & 13.5 & 15 & 18 & 19.5 \\
\hline & $\operatorname{MDD}\left(\mathrm{kg} / \mathrm{m}^{3}\right)$ & 1800 & 1760 & 1690 & 1620 & 1580 \\
\hline \multirow[t]{2}{*}{ S3 } & OMC (\%) & 10 & 12 & 15 & 17.5 & 20 \\
\hline & $\operatorname{MDD}\left(\mathrm{kg} / \mathrm{m}^{3}\right)$ & 1900 & 1860 & 1820 & 1700 & 1660 \\
\hline \multirow[t]{2}{*}{ S4 } & OMC (\%) & 16 & 17 & 22 & 23 & 25.2 \\
\hline & $\operatorname{MDD}\left(\mathrm{kg} / \mathrm{m}^{3}\right.$ & 1700 & 1640 & 1550 & 1510 & 1480 \\
\hline
\end{tabular}

\section{S1}

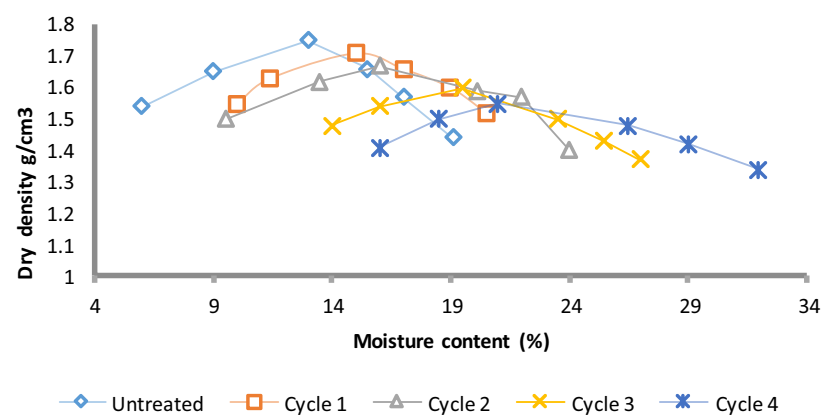

Fig. 4 Variation of density and moisture with heating/cooling cycles sample $\mathrm{S1}$

S2

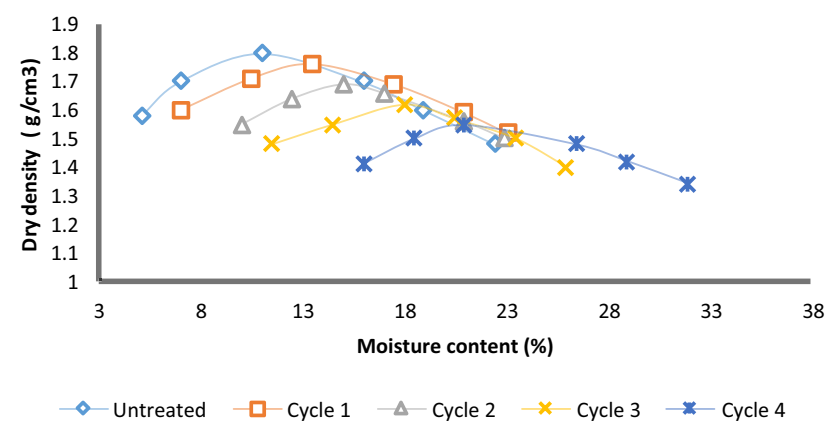

Fig. 5 Variation of density and moisture with heating/cooling cycles for sample S2

\subsection{Effect of repeated heating on California bearing ratio of the studied soils}

California Bearing ratio is essentially a measure of the shear strength of a material at a known density and moisture content. Table 5 presents the CBR characteristic of the soils before and after each heating and cooling cycle. It was observed that the CBR values of the soils generally
S3

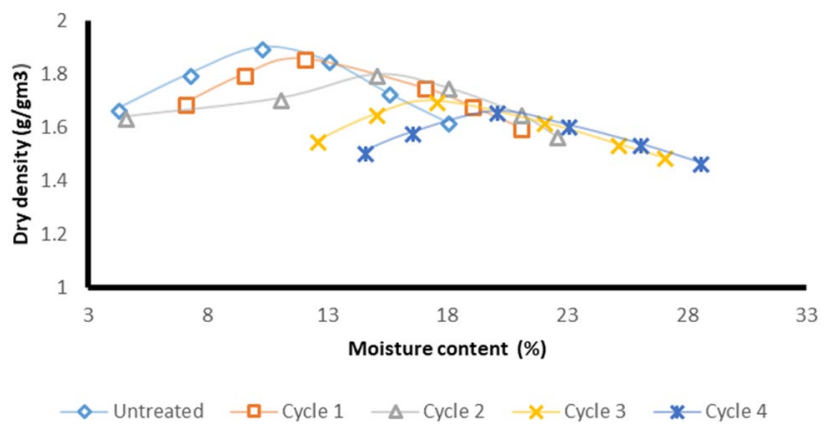

Fig. 6 Variation of MDD and OMC with heating/cooling cycles for sample S3

S4

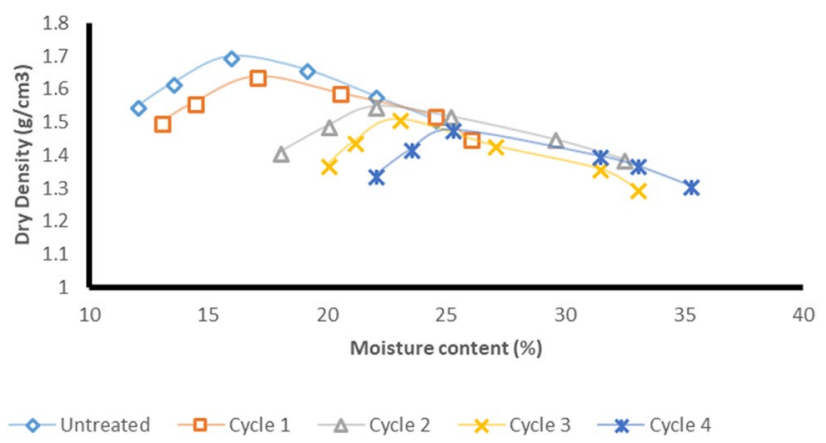

Fig. 7 Variation of MDD and OMC with heating/cooling cycles for sample $\mathrm{S} 4$

increased with heating cycle. This increase may be attributed to changes in microstructure or structural fabric of the clay minerals or particles of the soil. Repeated cycles of heating and cooling of the studied soils brought about an increase in CBR between 3.84\% and $23.51 \%$ after the 4th cycle. Sample S4 exhibited highest increment in CBR with heating cycles just as it exhibited the highest reduction in plasticity as explained above. This study also indicates 


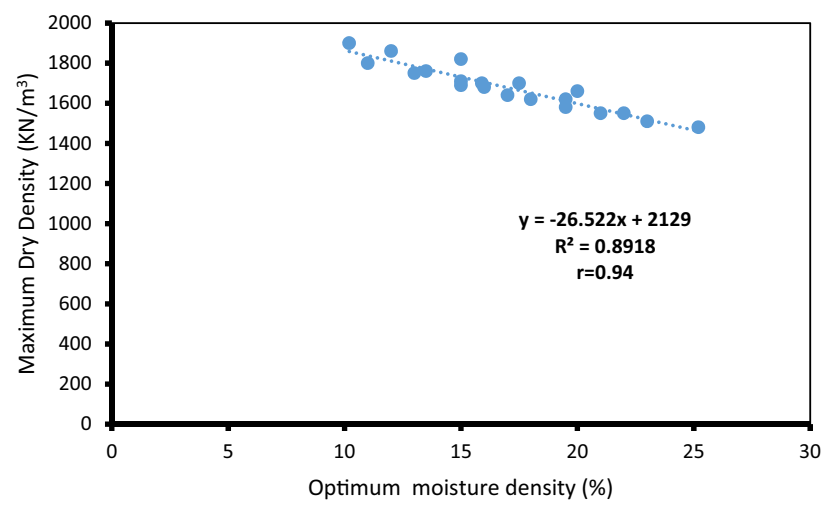

Fig. 8 Relationship between MDD and OMC for the four heating cycles

Table 5 California bearing ratio characteristic of each heating cycle

\begin{tabular}{lcccccc}
\hline CBR (\%) & Untreated Cycle 1 & Cycle 2 & Cycle 3 & Cycle 4 & $\begin{array}{l}\text { \% incre- } \\
\text { ment in } \\
\text { CBR }\end{array}$ \\
\hline S1 & 53.21 & 54.55 & 55.76 & 56.24 & 60.00 & 11.31 \\
S2 & 91.03 & 92.85 & 93.94 & 94.18 & 94.67 & 3.84 \\
S3 & 26.67 & 27.27 & 30.42 & 30.91 & 31.52 & 15.37 \\
S4 & 11.03 & 11.64 & 13.33 & 13.82 & 14.42 & 23.51 \\
\hline
\end{tabular}

that at higher moisture content (OMC) and lower MDD, the studied soils gained higher strength as a result of repeated heating. Heated samples are therefore likely to possess better shear strength and bearing capacity when compacted optimum moisture content.

\section{Conclusion}

This study investigates the effect of repeated heating and cooling on the properties of residual lateritic soils from Ilorin, Nigeria. The results of this study reveal that repeated heating and cooling cycles led to changes in the index and engineering properties of the lateritic soils. The particle size analysis showed that the unheated lateritic soils were well graded and contained variable amount of fines. Casagrande plasticity chart classified the unheated soils as inorganic clay of medium plasticity ( $\mathrm{CL}$ soil). Minor variations were observed in the grain size distribution characteristic of the lateritic soil after the four cycles of heating-cooling. The consistency limits, however, decreased significantly after the four cycles of heating - cooling. OMC and MDD increased steadily and decreased slightly, respectively, with repeated heatingcooling cycle. A comparison of the CBR values before and after the heating cycles also indicated a significant increase in CBR of the studied soils. Some of the changes observed in this study as a result of the heating and cooling cycles might be as results of changes morphology in the morphology of the lateritic soils such structural fabric of the clay minerals or particles of the soil. This study has further increased our understanding of effect of elevated temperature on the properties of soil. However, we intend to study the changes in the microstructural behaviour of the soil using SEM and clay mineralogy using XRD.

\section{Compliance with ethical standards}

Conflicts of interest The authors declare that they have no conflict of interest.

\section{References}

1. Gidigasu MD (1976) Laterite soil engineering: pedogenesis and engineering principles. Amsterdam Elsevier Scientific, New York

2. Adeyemi GO, Afolagboye LO, Chukwuemeka CA (2015) Geotechnical properties of non-crystalline coastal plain sand derived lateritic soils from Ogua, Niger Delta, Nigeria. African J Sci Technol Innov Dev 7:230-235. https://doi.org/10.1080/20421 338.2015.1078105

3. Osinubi KJ, Nwaiwu CM (2006) Design of compacted lateritic soil liners and covers. J Geotech Geoenvironmental Eng 132:203213. https://doi.org/10.1061/(ASCE)1090-0241(2006)132:2(203)

4. Mitchell JK, Soga K (2005) Fundamentals of soil behavior, 3rd edn. Wiley, New York

5. Gens A (2010) Soil-environment interaction in geotechnical engineering. Geotechnique 60:3-74

6. Attah IC, Etim RK (2020) Experimental investigation on the effects of elevated temperature on geotechnical behaviour of tropical residual soils. SN Appl Sci 2:370. https://doi. org/10.1007/s42452-020-2149-x

7. Haehnlein S, Bayer P, Blum P (2010) International legal status of the use of shallow geothermal energy. Renew Sust Energ Rev 14:2611-2625. https://doi.org/10.1016/j.rser.2010.07.069

8. Harbidge A, Jefferson I, Rogers C, Coates M (1996) A comparison of the heat dissipation performance of twin wall HDPE and earthenware cable ducts. In: Proceedings of 1996 transmission and distribution conference and exposition. IEEE, Los Angeles, pp 525-530

9. Graham J, Tanaka N, Crilly T, Alfaro M (2001) Modified Camclay modelling of temperature effects in clay. Can Geotech J 38:608-621

10. Aldaeef AA, Rayhani MT (2015) Hydraulic performance of compacted clay liners under simulated daily thermal cycles. J Environ Manag 162:171-178

11. William R (1997) Burning bush. Fire Eng 150:4

12. Zihms SG, Switzer C, Karstunen A, Tarantino M (2013) Understanding the effects of high temperature processes on the engineering properties of soils. In: Proceedings of the 18th international conference on soil mechanics and geotechnical engineering. Paris, pp 3427-3430 
13. Delage P, Sultan N, Cui YJ (2000) On the thermal consolidation of boom clay. Can Geotech J 37:343-354

14. Gadzama EW, Nuhu I, Yohanna P (2017) Influence of temperature on the engineering properties of selected tropical black clays. Arab J Sci Eng 42:3829-3838. https://doi.org/10.1007/s1336 9-017-2485-3

15. Abu-Zreig MM, Al-Akhras NM, Attom MF (2001) Influence of heat treatment on the behavior of clayey soils. Appl Clay Sci 20:129-135. https://doi.org/10.1016/S0169-1317(01)00066-7

16. Villar MV, Lloret A (2004) Influence of temperature on the hydromechanical behaviour of a compacted bentonite. Appl Clay Sci 26:337-350. https://doi.org/10.1016/j.clay.2003.12.026

17. Sultan N, Delage P, Cui YJ (2002) Temperature effects on the volume change behaviour of Boom clay. Eng Geol 64:135-145. https://doi.org/10.1016/S0013-7952(01)00143-0

18. Chen Z, Zhu H, Yan Z et al (2016) Experimental study on physical properties of soft soil after high temperature exposure. Eng Geol 204:14-22. https://doi.org/10.1016/j.enggeo.2016.01.014

19. Romero E, Villar MV, Lloret A (2005) Thermo-hydro-mechanical behaviour of two heavily overconsolidated clays. Eng Geol 81:255-268. https://doi.org/10.1016/j.enggeo.2005.06.011

20. Abuel-Naga H, Bergado D, Ramana $G$ et al (2006) Experimental evaluation of engineering behavior of soft Bangkok clay under elevated temperature. J Geotech Geoenvironmental Eng 132:902-910

21. Mon EE, Hamamoto S, Kawamoto KK et al (2013) Temperature effects on geotechnical properties of kaolin clay: simultaneous measurements of consolidation characteristics, shear stiffness and permeability using a modified oedometer. GSTF J Geol Sci 1:1-10. https://doi.org/10.5176/2335-6774_1.1.1

22. Vuilleumier F, Weatherill A, Crausaz B (2002) Safety aspects of railway and road tunnel: example of the Lotschberg railway tunnel and Mont-Blanc road tunnel. Tunn Undergr Sp Technol 17:153-158

23. Agence Nationale pour la Gestion des Dechets Radioactifs (2005) The Meuse-Haute Marne underground research laboratory. A scientific research tool for the study of deep geologic disposal of radioactive wastes

24. Oclon P, Taler D, Cisek P, Pilarczyk M (2015) FEM-based thermal analysis of underground power cables located in backfills made of different materials. Strength Mater 47:770-780

25. Oyinloye OA (2011) Geology and geotectonic setting of the basement complex rocks in South Western Nigeria: Implications on provenance and evolution. In: Earth and environmental sciences. IntechOpen, Rijeka, p 5

26. BSI (1990) BS 1377: Methods of testing soils for civil engineering purposes. BSI, London, UK

27. ISRM (1981) ISRM suggested methods: rock characterization. In: Brown ET (ed) Testing and monitoring. Pergamon, London

28. Skempton AW (1953) The colloidal "activity" of clays. In: 3rd International Conference of Soil Mechanics. Thomas Telford Publishing, Zurich, pp 57-61

29. Polidori E (2009) Reappraisal of the activity of clays. Activity chart. Soils Found 49:431-441. https://doi.org/10.3208/sandf .49 .431

30. Owoyemi OO, Adeyemi GO (2018) Characterisation of soils derived from different parent rocks from north central Nigeria. In: Proceedings of the institution of civil engineers - construction materials, pp 1-14

31. Cassagrande A (1948) Classification and identification of soil transaction, vol 113. ASCE, New York

Publisher's Note Springer Nature remains neutral with regard to jurisdictional claims in published maps and institutional affiliations. 